\title{
Article \\ Paternal Uniparental Isodisomy of Chromosome 2 in a Patient with CNGA3-Associated Autosomal Recessive Achromatopsia
}

\author{
Susanne Kohl ${ }^{1, *}$, Britta Baumann ${ }^{1}$, Francesca Dassie ${ }^{2}$, Anja K. Mayer ${ }^{1}$, Maria Solaki ${ }^{1}$, Peggy Reuter ${ }^{1}$, \\ Laura Kühlewein $^{1,3}$, Bernd Wissinger ${ }^{1}(\mathbb{D})$ and Pietro Maffei ${ }^{2}$ (D) \\ 1 Centre for Ophthalmology, Institute for Ophthalmic Research, University Tübingen, \\ 72076 Tübingen, Germany; britta.baumann@med.uni-tuebingen.de (B.B.); \\ anja.ka.mayer@gmail.com (A.K.M.); maria.solaki@med.uni-tuebingen.de (M.S.); \\ peggy.reuter@med.uni-tuebingen.de (P.R.); laura.kuehlewein@med.uni-tuebingen.de (L.K.); \\ bernd.wissinger@med.uni-tuebingen.de (B.W.) \\ 2 Department of Medicine (DIMED), University of Padua, 35121 Padua, Italy; francesca.dassie@unipd.it (F.D.); \\ pietro.maffei@unipd.it (P.M.) \\ 3 Centre for Ophthalmology, University Eye Hospital, University Tübingen, 72076 Tübingen, Germany \\ * Correspondence: susanne.kohl@med.uni-tuebingen.de
}

Citation: Kohl, S.; Baumann, B.; Dassie, F.; Mayer, A.K.; Solaki, M.; Reuter, P.; Kühlewein, L.; Wissinger, B.; Maffei, P. Paternal Uniparental Isodisomy of Chromosome 2 in a Patient with CNGA3-Associated Autosomal Recessive Achromatopsia. Int. J. Mol. Sci. 2021, 22, 7842. https://doi.org/10.3390/ijms22157842

\section{Academic Editors:}

Francesca Simonelli, Fracesco Testa and Marianthi Karali

Received: 16 June 2021

Accepted: 21 July 2021

Published: 22 July 2021

Publisher's Note: MDPI stays neutral with regard to jurisdictional claims in published maps and institutional affiliations.

Copyright: (C) 2021 by the authors. Licensee MDPI, Basel, Switzerland. This article is an open access article distributed under the terms and conditions of the Creative Commons Attribution (CC BY) license (https:/ / creativecommons.org/licenses/by/ $4.0 /)$.

\begin{abstract}
Achromatopsia (ACHM) is a rare autosomal recessively inherited retinal disease characterized by congenital photophobia, nystagmus, low visual acuity, and absence of color vision. ACHM is genetically heterogeneous and can be caused by biallelic mutations in the genes CNGA3, CNGB3, GNAT2, PDE6C, PDE6H, or ATF6. We undertook molecular genetic analysis in a single female patient with a clinical diagnosis of ACHM and identified the homozygous variant c.778G>C;p.(D260H) in the CNGA3 gene. While segregation analysis in the father, as expected, identified the CNGA3 variant in a heterozygous state, it could not be displayed in the mother. Microsatellite marker analysis provided evidence that the homozygosity of the CNGA3 variant is due to partial or complete paternal uniparental isodisomy (UPD) of chromosome 2 in the patient. Apart from the ACHM phenotype, the patient was clinically unsuspicious and healthy. This is one of few examples proving UPD as the underlying mechanism for the clinical manifestation of a recessive mutation in a patient with inherited retinal disease. It also highlights the importance of segregation analysis in both parents of a given patient or especially in cases of homozygous recessive mutations, as UPD has significant implications for genetic counseling with a very low recurrence risk assessment in such families.
\end{abstract}

Keywords: achromatopsia; ACHM; uniparental isodisomy; chromosome 2; CNGA3

\section{Introduction}

Achromatopsia (ACHM; synonymous with rod monochromatism; ACHM2, MIM 216900; ACHM3, MIM 262300; ACHM4, MIM 613856; ACHM5/COD4, MIM 613093; ACHM6/RCD3A, MIM 610024; and ACHM7, IM616517) is a rare, autosomal recessive disorder with an estimated prevalence of 1 in 30,000 to 1:50,000. It is a congenital retinal disease affecting only the cone photoreceptor, and photophobia and nystagmus are the first symptoms manifesting within the first weeks or months of life. Due to lack of cone photoreceptor function, ACHM is characterized by color blindness and low visual acuity (20/400-20/200 Snellen equivalent). ACHM was believed to be a stationary disease, but recent studies by optical coherence tomography have shown that there is progressive degeneration of the central retina and cone photoreceptors [1-5].

$\mathrm{ACHM}$ is genetically heterogeneous and known to be caused by mutations in six genes: CNGA3, CNGB3, GNAT2, PDE6C, PDE6H, and ATF6 [6-13]. The first five genes encode important functional components of the cone phototransduction cascade (G-protein transducin GNAT2 (guanine nucleotide-binding protein G(t) subunit alpha 2; MIM 139340); cone-photoreceptor phosphodiesterase catalytic subunit PDE6C (cone cyclic GMP-specific 
$3^{\prime}, 5^{\prime}$ cyclic phosphodiesterase alpha-prime; MIM 600827) and inhibitory subunit PDE6H (cone cyclic GMP-specific phosphodiesterase gamma; MIM 601190); cone photoreceptor cyclic nucleotide gated cation (CNG) channel CNGA3 (cyclic nucleotide-gated cation channel alpha 3; MIM 600053) and CNGB3 (cyclic nucleotide-gated cation channel beta 3; MIM 605080)), while the ubiquitously expressed transcription factor ATF6 (activating transcription factor 6; MIM 605537) is known for its function in the unfolded protein response and endoplasmic reticulum stress response [14,15].

In Europe and the United States, biallelic mutations in CNGB3 are the major cause of ACHM, accounting for $50-60 \%$ of cases, especially due to a common founder mutation c.1148delC, followed by biallelic mutations in CNGA3, which are found in $30 \%$ of ACHM patients in these populations [16,17]. In contrast, biallelic mutations in CNGA3 account for the majority of ACHM patients of Chinese (80\%) and Israeli/Palestinian (84\%) origin [18,19]. The other ACHM-associated genes play a minor role, being responsible for only $0.5-3 \%$ of cases [16].

CNGA3- and CNGB3-associated ACHM are in the focus, as several AAV-based gene supplementation therapy trials are ongoing (NCT02610582, NCT03758404, NCT02935517, NCT02599922), and one trial has already been successfully finished and published [20].

\section{Results}

An Italian female patient with a clinical diagnosis of ACHM without family history of this condition was referred to the Centre for Ophthalmology Tübingen for genetic testing in a research setting. The patient suffered from photophobia since birth and was diagnosed to have ACHM at the age of 10 years. Her visual acuity at the age of 18 was $20 / 200$ Snellen equivalent with a correction of +3.00 diopters in both eyes. The patient exhibited a fine pendular nystagmus that was more pronounced when looking at distant targets. Intraocular pressure was within normal limits in both eyes $(14 \mathrm{mmHg})$. Anterior and posterior segment examination was unremarkable except for the margins of the optic discs that were not absolutely sharp. Full-field electroretinogram showed symmetrical severely reduced cone responses and abnormalities in the rod responses. Dark adaptation curves were typical for ACHM. Color vision testing using a Panel D-15 test and a Nagel anomaloscope exhibited findings typical for ACHM. Kinetic visual field testing showed normal outer visual field boundaries.

Genetic research testing revealed an apparent homozygous missense variant c.778G $>C$; p.(D260H) in exon 7 of CNGA3. The variant has not been reported in the literature, various mutation databases (i.e., HGMD ${ }^{\circledR}$ —Human Gene Mutation Database, ClinVar https:/ / www.ncbi.nlm.nih.gov / clinvar (accessed on 16 June 2021), LOVD ${ }^{3}$ - Leiden Open Variation Database https:/ / www.LOVD.nl/CNGA3 (accessed on 16 June 2021)), nor has it been observed in population databases (i.e., gnomAD browser; https:/ /gnomad.broadinstitute. org/gene/ENSG00000144191 (accessed on 16 June 2021)). The variant affects an amino acid residue in transmembrane domain S3 of the CNGA3 polypeptide. This amino acid residue is conserved not only in all CNGA3 orthologs but also in rod-photoreceptor-specific CNGA1 paralogs (Figure 1C).

Segregation analysis by PCR and Sanger sequencing proved the father to be a heterozygous carrier, while the variant could not be detected in the mother (Figure 1A). A heterozygous deletion in the mother explaining the apparent homozygosity of the mutation in the patient was ruled out by long-distance PCR and a SYBR Green-based quantitative real-time PCR copy number assay. Segregation analysis and haplotype reconstruction for ten microsatellite markers covering the entire chromosome 2 in the patient and both parents revealed homozygosity in the patient for all tested markers for the paternal allele, providing evidence for complete (or partial) paternal uniparental isodisomy (UPD) of chromosome 2 in the patient (Figure 1B). 
A

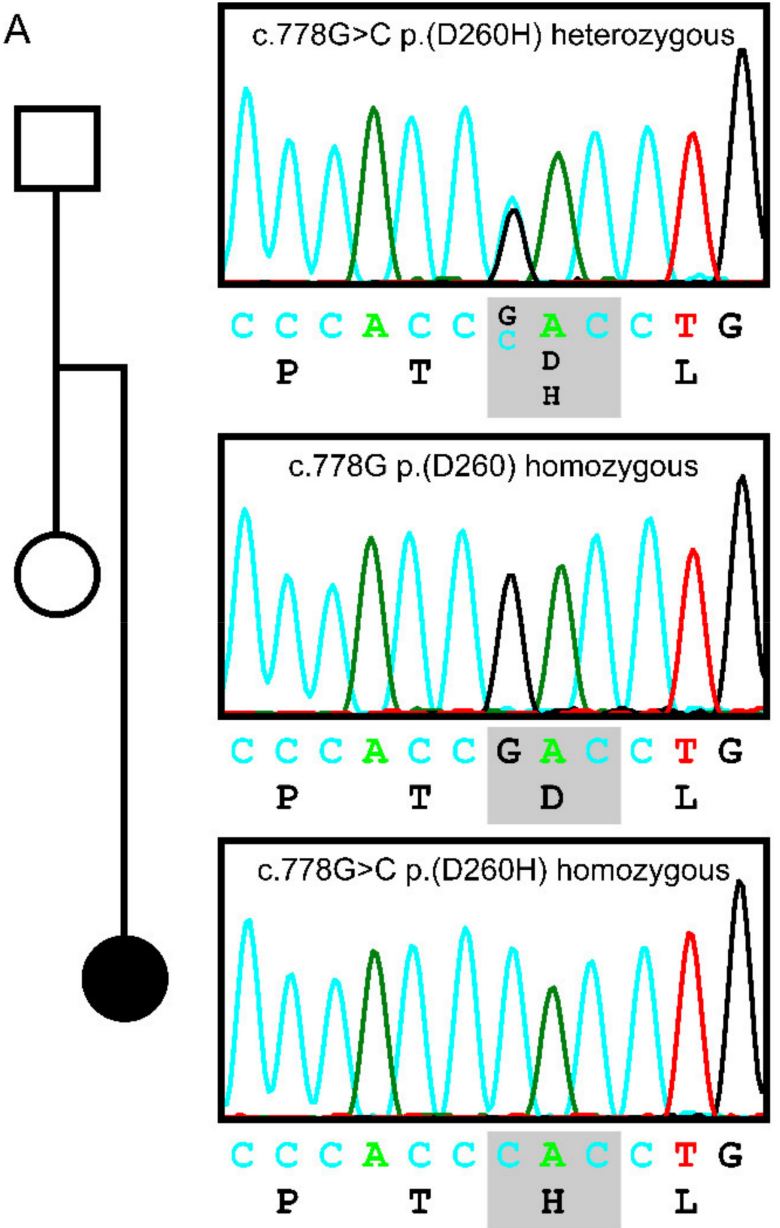

B

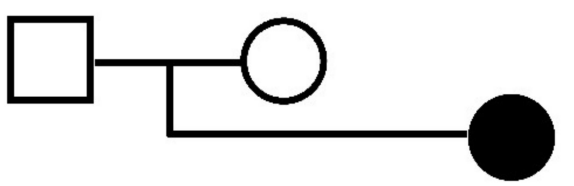

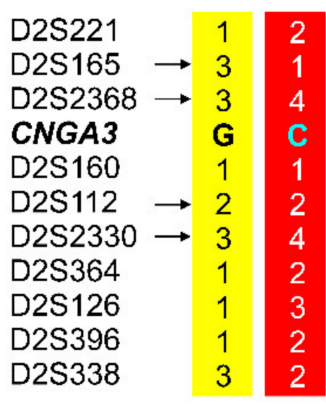

C

\section{HS_CNGA3}

Rn_Cnga3

Mm Cnga3

Gg_CNGA3

$x t$ cnga 3

Dr cnga3a

Din_CngA

Ce tax -4

Hs CNGA1

Rn Cnga1

Mm Cngal

Gg_CNGA1

$X t$ cngal

Dr_cnga1b

$2 / 3$
$2 / 2$
$1 / 2$
$\mathbf{G} / \mathbf{G}$
$1 / 1$
$1 / 1$
$1 / 2$
$2 / 3$
$2 / 3$
$2 / 2$
$2 / 3$

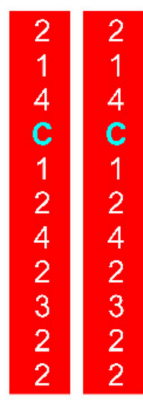

1

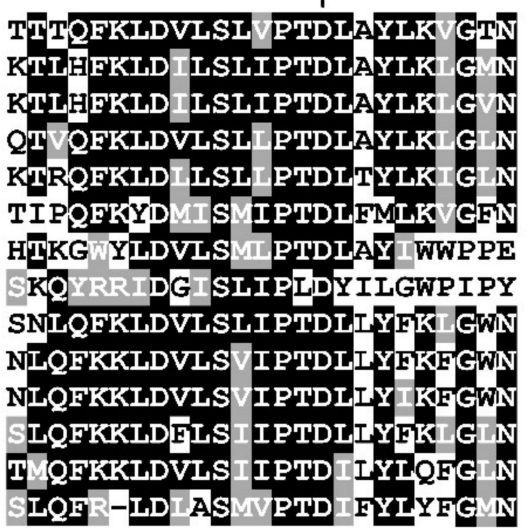

Transmembrane domain S3

Figure 1. Segregation analysis, haplotype reconstruction, and conservation of CNGA3 c.778G>C;p.(D260H). (A) Segregation analysis via Sanger sequencing for CNGA3 exon 7 in family CHRO978, as shown by the electropherograms obtained from both parents and the index patient. The father is heterozygous for the variant c.778G>C (top), while the mother does not carry this variant (middle). The affected daughter is homozygous for this variant in CNGA3 (bottom). (B) Haplotype reconstruction of chromosome 2. Microsatellite marker analysis in the patient and both parents demonstrated paternal uniparental isodisomy of chromosome 2, either fully or partially. The patient inherited two copies (or partial chromosomal segments) of the paternal chromosome (red haplotype) carrying and flanking the CNGA3 variant c.778G>G;p.(D260H), while the maternal chromosome was not or only partially transmitted. Informative markers are marked by an arrow. Of note, the two haplotypes of the mother could not be reconstructed. (C) Conservation of the mutated amino acid residue CNGA3 p.D260H among CNGA3 and CNGA1 polypeptides across various species. Protein sequence alignment was performed using Clustal Omega (https://www.ebi.ac.uk/Tools/msa/clustalo/ (accessed on 16 June 2021)) and BoxShade (https:/ / embnet.vital-it.ch/software/BOX_form.html (accessed on 16 June 2021)). Reference sequences from NCBI (https:/ / www.ncbi.nlm.nih.gov/ (accessed on 16 June 2021)): CNGA3: H. sapiens NP_001289.1, R. norvegicus NP_445947.1, M. musculus NP_001268939.1,G. gallus NP_990552.1, X. tropicalis XP_031752880.1, D. rerio XP_005166141.1, D. melanogaster NP_477116.1, C. elegans NP_499033.1, CNGA1: H. sapiens NP_001366199.1, R. norvegicus NP_445949.2, M. musculus NP_031749.2, G. gallus NP_990551.1, X. tropicalis XP_017950934.1, D. rerio XP_701036.4.

The variant is predicted to be disease-causing by various tools (i.e., SIFT, PolyPhen, Provean) and classified as likely pathogenic according to the ACMG (American College of Medical Genetics) guidelines. In vitro heterologous expression and analysis via a bioluminescent calcium reporter assay of the $\mathrm{CNGA}_{\mathrm{D} 260 \mathrm{H}}$ mutant versus wild-type CNGA3 in HEK293 (human embryonic kidney) cells provided evidence that this variant results in complete loss of channel function (Figure 2A). Similarly, another amino acid substitution at the very same amino acid residue-c.778G $>$ A;p.(D260N) - had previously been shown to result in complete channel function loss in in vitro studies [21,22]. Loss of CNGA3 or 
CNGA3 function cannot be compensated, as CNGA3 encodes for the channel forming A subunit of the cone photoreceptor CNG channel. Using immunocytochemistry, we were able to confirm the expression of the channel mutant CNGA3 ${ }_{\mathrm{D} 260 \mathrm{H}}$ in transfected HEK293 cells despite the fact that a calcium influx was not detectable in the aequorin-based bioassay (Figure 2B).

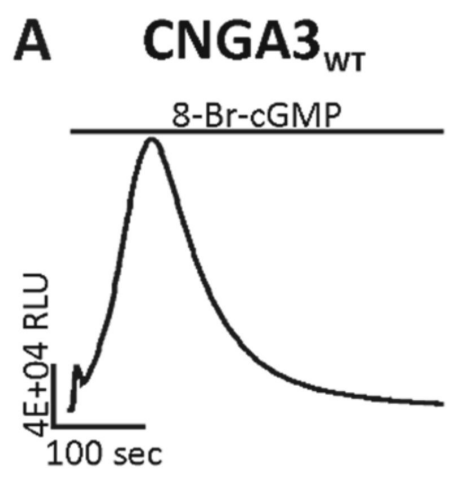

CNGA3 $_{\text {D260H }}$
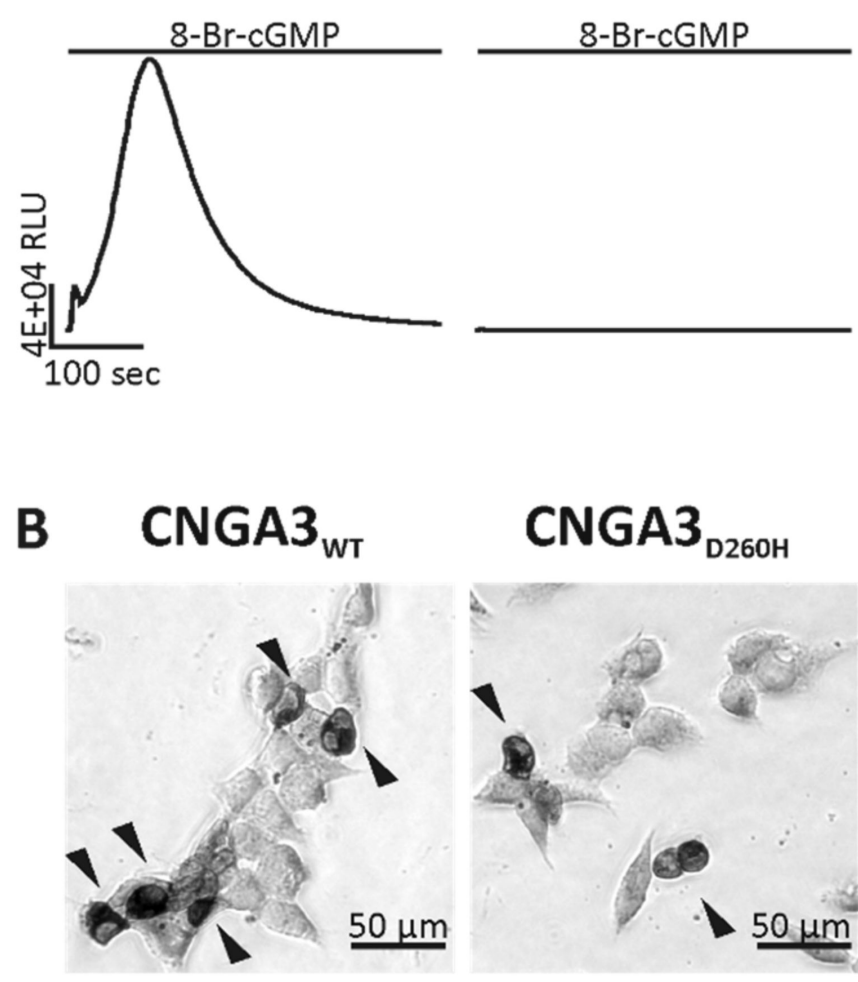

\section{no CNGA3}

8-Br-cGMP

Figure 2. Aequorin-mediated luminescence signals and immunocytochemical staining of wildtype (WT) and mutant (D260H) CNGA3 channels. (A) The luminescence signal of HEK293 cells either expressing aequorin and $\mathrm{CNGA}_{\mathrm{WT}}$ (left) or aequorin and $\mathrm{CNGA} 3_{\mathrm{D} 260 \mathrm{H}}$ (middle) or aequorin only (right) was recorded for a duration of $400 \mathrm{~s}$. Application of the CNGA3 channel ligand 8bromoguanosine-3', $5^{\prime}$-cyclic monophosphate (8-Br-cGMP) $6 \mathrm{~s}$ after starting the recording resulted in an increase of the luminescence signal only in cells expressing CNGA3 ${ }_{W T}$. HEK293 cells expressing mutant $\mathrm{CNGA} 3{ }_{\mathrm{D} 260 \mathrm{H}}$ displayed no luminescence signal classifying the variant as non-functional. Cells expressing aequorin-only served as a negative control. RLU: relative light units. (B) Detection of CNGA3 protein expression was conducted by immunocytochemical diaminobenzidine staining. HEK293 cells expressing the CNGA3 channel protein are marked with an arrow head. Expression of the channel mutant $\mathrm{CNGA3}_{\mathrm{D} 260 \mathrm{H}}$ in HEK293 cells could be confirmed (middle). $\mathrm{CNGA}_{\mathrm{WT}^{-}}$ expressing cells (left) and cells expressing no CNGA3 channel (right) served as a positive and negative controls, respectively.

Upon this finding, we initiated a general clinical investigation and family history of the patient when she was 49 years old. Her paternal grandmother had dextrocardia and supernumerary kidneys with end-stage kidney failure on dialytic therapy. The mother underwent nephrectomy for kidney cancer. There was no parental consanguinity, nor were any visual disturbances reported among family members. The patient had a regular growth for weight and height, as well as age of menarche and menstrual cycles. She reported allergy to house dust and a history of migraines that was treated with triptans as needed. She suffered from photophobia and nystagmus since the first weeks of life. At the age of 10, the patient was diagnosed with ACHM. The visual disturbances remained stable over the years 
and the patient was still independent in daily living activities. On physical examination, the anthropometric parameters were within normal limits (weight $45.4 \mathrm{~kg}$; height $153 \mathrm{~cm}$; BMI 19.2). No significant dysmorphisms of the head or arms were observed. She had a normal blood pressure $(120 / 70 \mathrm{mmHg})$ and heart rate $\left(76 \mathrm{~m}^{\prime}\right)$. The clinical examination of the neck, chest, heart, abdomen, and neurological system were unremarkable. A general laboratory investigation including white blood cell count, platelet count test, hemoglobin, glycaemia and lipid profile, thyroid-stimulating hormone, electrolytes, and kidney and liver function tests was unremarkable. Instrumental investigations by chest $\mathrm{X}$-ray, electrocardiography, echocardiography, and thyroid and abdominal ultrasound showed multiple bilateral kidney cysts with a maximum diameter of $14 \mathrm{~mm}$.

\section{Discussion}

Uniparental isodisomy can be disease-causing due to disrupted imprinting or unmasking of recessive mutations. The patient in this study presented with typical symptoms of autosomal recessive ACHM, and a homozygous novel missense variant c.778G $>\mathrm{G}$; p.(D260H) in CNGA3 was identified. Functional analysis showed that this variant results in complete function loss of heterologously expressed mutant CNG channels indicating that this missense variant is a true pathogenic mutation. Segregation analysis and haplotype reconstruction provided evidence for complete or partial paternal UPD of chromosome 2, thereby unmasking the $C N G A 3$ mutation as the cause of the cone photoreceptor disease due to inheritance of two identical chromosomes (or partial chromosomal segments) from the father, while the maternal chromosome (or partial chromosomal segments) was lost.

Uniparental isodisomy was thought to be a rare phenomenon, but recent data suggest that it may be twice as common as previously expected, with a prevalence of approximately 1 in 2000 births [23].

While it is disease-relevant in imprinting disease, there is often no disease associationexcept for manifesting recessive mutations. A comprehensive literature search showed that several cases of UPD of chromosome 2 have been reported, some reflecting a similar situation as in our patient, where a recessive mutation manifests in the patient due to the UPD by inheriting two copies of a recessive mutation by one parent [24-26], but also generally healthy individuals have been identified by a genome-wide SNP scan or parentage testing [27-29]. Several genes have been predicted (http:/ / www.geneimprint. $\mathrm{com} /$ site/genes-by-species (accessed on 16 June 2021); i.e., OTX1, VAX2, CYP1B1) or experimentally shown to be imprinted on chromosome 2 (i.e., LRRTM1, GPR1, ZDBF2), but none of these have been shown to be associated with a disease caused by imprinting (https:/ / www.omim.org/ (accessed on 16 June 2021)). They rather result in disease due to classical point mutations (e.g., mutations in CYP1B1 result in glaucoma [26], mutations in $A B C G 8$ are associated with sitosterolemia [30]), or knockout animals have been shown to develop a phenotype (i.e., Otx1 knockout mice show epileptic behavior [31], Vax2 knockout results in abnormal retinal and optic nerve development [32], and Zfp36l2 knockout is embryonically lethal [33]). These findings are in line with the fact that our patient is of general good health apart from the isolated retinal phenotype of ACHM.

It has been suggested that UPD is associated with an older maternal age at conception or an advanced parental age in general [34,35]. This does not hold true for our patient, as the parents were in their early and mid-twenties when the patient was born.

The herein presented case is one of very few examples for this mechanism observed and described in inherited retinal dystrophy [36-40], including UPD of chromosome 2 in a patient with a homozygous mutation in MERTK [41], and the first for ACHM.

\section{Materials and Methods}

The study was conducted in accordance with the Declaration of Helsinki, with approval from the ethics committee of the University of Tübingen (project nos. 349/2003V and 116/2015BO2). Venous blood samples of the index patient and both parents were collected upon written informed consent. 
Ophthalmological examinations included visual acuity testing, intraocular pressure measurement, anterior and posterior segment examination, full-field electroretinography, dark adaptation curves, color vision testing using a Panel D-15 test and a Nagel anomaloscope, and kinetic visual field testing.

Patient's medications; allergies; and past medical, surgical, social, and family history were reviewed. Anthropometric measurements were taken with the patient wearing only light clothes without shoes. Height was measured to the nearest $0.01 \mathrm{~m}$ using a stadiometer. Body weight was determined to the nearest $0.1 \mathrm{~kg}$ using a calibrated balance beam scale. Body mass index was calculated as $\mathrm{kg} / \mathrm{m}^{2}$, where $\mathrm{kg}$ is the patient's weight in kilograms and $\mathrm{m}^{2}$ is the height in meters squared. Blood pressure and heart rate were recorded after $10 \mathrm{~min}$ rest at the brachial artery of the dominant arm using a validated semi-automated oscillometric device in the seated position. A thorough and systematic clinical examination was done. Complete blood count, protein electrophoresis, serum lipids, renal and liver function, blood glucose and $\mathrm{HbA} 1 \mathrm{c}$ levels, electrolytes, thyroid function, and urine analysis were measured by standard laboratory procedures. Instrumental investigations included chest X-ray, electrocardiography, echocardiography, and thyroid and abdominal ultrasound.

Sanger sequencing of all coding exons of $C N G A 3$ on an ABI3130 capillary sequencer (Applied Biosystems, Thermo Fisher Scientific, Waltham, MA, USA) was performed on PCR-amplified genomic DNA obtained from venous blood as previously described [7,21]. Segregation analysis was also performed by PCR and Sanger sequencing (Figure 1A). In addition, the common ACHM-associated variant CNGB3 c.1148del was excluded.

The CNGA3 variant was classified according to the standards and guidelines provided by the American College of Medical Genetics and Genomics (ACMG) and the Association for Molecular Pathology (AMP) [42]. The potential impact and pathogenicity of the missense change was further assessed by applying various prediction tools embedded in Alamut Visual software (Interactive Biosoftware, Rouen, France), literature search, and conservation between various CNGA3 and CNGA1 orthologs and paralogs. The variant was annotated according to NCBI reference sequence for CNGA3 (NM_001298.3, ENST00000272602.7, GRCh38 genome assembly) comprising seven coding exons.

To test for a putative heterozygous deletion of $C N G A 3$ exon 7 in the mother and the patient, we performed a custom-designed amplicon-based assay for CNGA3 exon 7 applying the QuantiTect SYBR Green PCR Kit (QIAGEN, Hilden, Germany), primers $5^{\prime}$-CTCAAGAGCCTCCCAGACAA- ${ }^{\prime}$ and $5^{\prime}$-AGCTTCAGCACCAGCTCCA- ${ }^{\prime}$ and SDC4 as reference gene, as previously described for CNGB3 [16].

For human chromosome 2 segregation analysis, ten microsatellite markers (D2S2211, D2S165, D2S2368, D2S160, D2S112, D2S2330, D2S364, D2S126, D2S396, D2S338) covering the entire chromosome 2 were selected from the ABI PRISM ${ }^{\circledR}$ Linkage Mapping Set (Applied Biosystems, Thermo Fisher Scientific) and genotyped by PCR amplification and fragment sizing on an ABI3130 capillary sequencer (Applied Biosystems, Thermo Fisher Scientific) in Gene Scan mode. Microsatellite marker typing is presented in Supplementary Figures S1 and S2, Table S1.

Wild-type and p.D260H mutant CNGA3 channel functionality and surface expression were evaluated in transiently transfected human embryonic kidney (HEK293) cells using an aequorin-based luminescence bioassay. The generation of the wild-type human CNGA3 expression construct was described previously [43]. In vitro mutagenesis PCR was performed to generate the mutant $\mathrm{CNGA} 3$ expression construct $\mathrm{CNGA}_{\mathrm{D} 260 \mathrm{H}}$. The establishment of an expression construct for cytosolic apo-aequorin was described previously [44]. HEK293 cells (DSMZ-German Collection of Microorganisms and Cell Cultures $\mathrm{GmbH}$, Braunschweig, Germany) were cultured in Dulbecco's modified Eagle's medium (Thermo Fisher Scientific) supplemented with 10\% fetal calf serum (Thermo Fisher Scientific), $1 \%$ penicillin/streptomycin (Thermo Fisher Scientific), and 1\% amphotericin B (Pan Biotech, Aidenbach, Germany) at $5 \% \mathrm{CO}_{2}$ at $37{ }^{\circ} \mathrm{C}$. HEK293 cells were seeded at a density of $3.5 \times 10^{5}$ cells per 24 well and transfected on the next day with $1 \mu \mathrm{g}$ wild-type 
or mutant CNGA3 and $1.5 \mu \mathrm{g}$ of apo-aequorin expression plasmid using Lipofectamine ${ }^{\mathrm{TM}}$ 2000 (Thermo Fisher Scientific) following the manufacturer's instructions [44]. Control cells were transfected only with $2 \mu \mathrm{g}$ apo-aequorin expression plasmid. Six hours after transfection start, cells were re-plated in a white opaque 96 well plate. After overnight incubation, transfected cells were treated with $3 \mathrm{mM}$ sodium butyrate (Sigma-Aldrich, St Louis, MO, USA) for $24 \mathrm{~h}$ to enhance protein expression. Prior to the luminescence assay, cells were washed with calcium imaging buffer (CI; $150 \mathrm{mM} \mathrm{NaCl}, 5 \mathrm{mM} \mathrm{KCl}, 2 \mathrm{mM}$ $\mathrm{CaCl}_{2}, 2 \mathrm{mM}, \mathrm{MgCl}_{2}, 10 \mathrm{mM}$ HEPES (pH 7.4), $30 \mathrm{mM}$ glucose) and incubated with $8 \mu \mathrm{M}$ coelenterazine (Biomol GmbH, Hamburg, Germany) in $\mathrm{CI}$ for $4 \mathrm{~h}$ at $37^{\circ} \mathrm{C}$ to reconstitute the apo-aequorin. Following washing with $\mathrm{CI}$ and $\mathrm{CI}$-high $\mathrm{Ca}^{2+}$ (CI buffer with $10 \mathrm{mM}$ $\left.\mathrm{Ca}^{2+}\right), 190 \mu \mathrm{L}$ of $\mathrm{CI}$-high $\mathrm{Ca}^{2+}$ per 96 well was added for the subsequent luminescence bioassay. Measurements were performed with the LUMIstar ${ }^{\circledR}$ Omega luminescence plate reader (BMG Labtech $\mathrm{GmbH}$, Ortenberg, Germany) at $37^{\circ} \mathrm{C}$. Luminescence was detected $6 \mathrm{~s}$ before and $394 \mathrm{~s}$ after automatic application of $10 \mu \mathrm{L} 100 \mathrm{mM}$ 8-bromoguanosine--3', $5^{\prime}$ cyclic monophosphate (8-Br-cGMP; BIOLOG Life Science Institute, Bremen, Germany)-a membrane-permeable CNG channel agonist. Samples were measured in triplicate, and three independent transfections were performed.

CNGA3 protein expression was verified by immunocytochemistry. HEK293 cells were seeded at a density of $3.5 \times 10^{5}$ cells per 24 well and transfected on the next day, as described above using $2 \mu \mathrm{g}$ wild-type or mutant CNGA3 expression construct. Following treatment with $3 \mathrm{mM}$ sodium butyrate for $24 \mathrm{~h}$, immunocytochemical staining was performed as previously described [45]. CNGA3 was detected using the custom primary antibody SA3899 and the horseradish peroxide-coupled goat anti-rabbit antibody (Merck KGaA, Darmstadt, Germany). For visualization, we performed a diaminobenzidine (DAB; Sigma Aldrich $\mathrm{GmbH}$, Munich, Germany) staining, applying $0.005 \% \mathrm{DAB}$ and $0.12 \%$ hydrogen peroxide in phosphate-buffered saline.

\section{Conclusions}

We herein report a unique case of ACHM due to UPD of chromosome 2. UPD is a rare phenomenon due to inheritance of both chromatids of a single chromosome from one parent-here, the paternal chromosome 2, while the maternal chromosome was not transmitted or lost from the zygote. UPD thus uncovered a recessive mutation present in just one parent-here, the missense variant c.778G > C; p.(D260H) in CNGA3 in the father, causing ACHM in the index patient. It is one of very few examples for this mechanism observed and described in inherited retinal dystrophy and the first for ACHM. The detection of UPD highlights the importance of segregation analysis and has significant implications for genetic counseling with a very low recurrency risk assessment in such families.

Supplementary Materials: The following are available online at https:/ /www.mdpi.com/article/10 .3390/ijms22157842/s1.

Author Contributions: Conceptualization: S.K., P.R., B.W.; investigation: S.K., F.D., B.B., A.K.M., M.S., L.K., P.M.; resources: B.W., P.M.; writing-original draft preparation: S.K.; writing-review and editing: S.K., F.D., A.K.M., M.S., P.R., L.K., B.W., P.M.; visualization: B.B., M.S., S.K.; supervision: S.K., P.R., B.W., P.M.; funding acquisition: S.K. All authors have read and agreed to the published version of the manuscript.

Funding: The project was funded in parts by the Deutsche Forschungsgemeinschaft project 39853967 (KO 2176/3-1) within the SPP2127 initiative. We acknowledge support by the Open Access Publishing Fund of the University of Tübingen.

Institutional Review Board Statement: The study was conducted according to the guidelines of the Declaration of Helsinki and approved by the Ethics Committee of the University of Tübingen, Germany (project no. 349/2003V, 22 September 2003 and 116/2015BO2116/2015BO2, 15 June 2018). 
Informed Consent Statement: Written informed consent was available for all three subjects involved in this study.

Data Availability Statement: Any data presented in this study are available on request from the corresponding author.

Acknowledgments: We would like to thank emeritus Balder Gloor, Department of Ophthalmology, University of Zurich Faculty of Medicine, Zurich, Switzerland, for initial ophthalmologic examination.

Conflicts of Interest: The authors declare no conflict of interest related to this project.

\section{References}

1. Thiadens, A.A.; Somervuo, V.; van den Born, L.I.; Roosing, S.; van Schooneveld, M.J.; Kuijpers, R.W.; van Moll-Ramirez, N.; Cremers, F.P.; Hoyng, C.B.; Klaver, C.C. Progressive loss of cones in achromatopsia: An imaging study using spectral-domain optical coherence tomography. Investig. Ophthalmol. Vis. Sci. 2010, 51, 5952-5957. [CrossRef]

2. Thomas, M.G.; McLean, R.J.; Kohl, S.; Sheth, V.; Gottlob, I. Early signs of longitudinal progressive cone photoreceptor degeneration in achromatopsia. Br. J. Ophthalmol. 2012, 96, 1232-1236. [CrossRef] [PubMed]

3. Sundaram, V.; Wilde, C.; Aboshiha, J.; Cowing, J.; Han, C.; Langlo, C.S.; Chana, R.; Davidson, A.E.; Sergouniotis, P.I.; Bainbridge, J.W.; et al. Retinal structure and function in achromatopsia: Implications for gene therapy. Ophthalmology 2014, 121, 234-245. [CrossRef]

4. Aboshiha, J.; Dubis, A.M.; Cowing, J.; Fahy, R.T.; Sundaram, V.; Bainbridge, J.W.; Ali, R.R.; Dubra, A.; Nardini, M.; Webster, A.R.; et al. A prospective longitudinal study of retinal structure and function in achromatopsia. Investig. Ophthalmol. Vis. Sci. 2014, 55, 5733-5743. [CrossRef] [PubMed]

5. Zobor, D.; Werner, A.; Stanzial, F.; Benedicenti, F.; Rudolph, G.; Kellner, U.; Hamel, C.; Andréasson, S.; Zobor, G.; Strasser, T.; et al. RD-CURE Consortium. The clinical phenotype of CNGA3-related achromatopsia: Pretreatment characterization in preparation of a gene replacement therapy trial. Investig. Ophthalmol. Vis. Sci. 2017, 58, 821-832. [CrossRef]

6. Kohl, S.; Marx, T.; Giddings, I.; Jägle, H.; Jacobson, S.G.; Apfelstedt-Sylla, E.; Zrenner, E.; Sharpe, L.T.; Wissinger, B. Total colourblindness is caused by mutations in the gene encoding the $\alpha$-subunit of the cone photoreceptor cGMP-gated cation channel. Nat. Genet. 1998, 19, 257-259. [CrossRef] [PubMed]

7. Kohl, S.; Baumann, B.; Broghammer, M.; Jägle, H.; Sieving, P.; Kellner, U.; Spegal, R.; Anastasi, M.; Zrenner, E.; Sharpe, L.T.; et al. Mutations in the CNGB3 gene encoding the $\beta$-subunit of the cone photoreceptor cGMP-gated channel are responsible for achromatopsia (ACHM3) linked to chromosome 8q21. Hum. Mol. Genet. 2000, 9, 2107-2116. [CrossRef]

8. Sundin, O.H.; Yang, J.M.; Li, Y.; Zhu, D.; Hurd, J.N.; Mitchell, T.N.; Silva, E.D.; Maumenee, I.H. Genetic basis of total colourblindness among the Pingelapese islanders. Nat. Genet. 2000, 25, 289-293. [CrossRef] [PubMed]

9. Kohl, S.; Baumann, B.; Rosenberg, T.; Kellner, U.; Lorenz, B.; Vadalà, M.; Jacobson, S.G.; Wissinger, B. Mutations in the cone photoreceptor G-protein $\alpha$-subunit gene GNAT2 in patients with achromatopsia. Am. J. Hum. Genet. 2002, 71, 422-425. [CrossRef]

10. Thiadens, A.A.; den Hollander, A.I.; Roosing, S.; Nabuurs, S.B.; Zekveld-Vroon, R.C.; Collin, R.W.; de Baere, E.; Koenekoop, R.K.; van Schooneveld, M.J.; Strom, T.M.; et al. Homozygosity mapping reveals PDE6C mutations in patients with early-onset cone photoreceptor disorders. Am. J. Hum. Genet. 2009, 85, 240-247. [CrossRef]

11. Chang, B.; Grau, T.; Dangel, S.; Hurd, R.; Jurklies, B.; Sener, E.C.; Andreasson, S.; Dollfus, H.; Baumann, B.; Bolz, S.; et al. A homologous genetic basis of the murine Cpfl1 mutant and human achromatopsia linked to mutations in the PDE6C gene. Proc. Natl. Acad. Sci. USA 2009, 106, 19581-19586. [CrossRef]

12. Kohl, S.; Coppieters, F.; Meire, F.; Schaich, S.; Roosing, S.; Brennenstuhl, C.; Bolz, S.; van Genderen, M.M.; Riemslag, F.C.; European Retinal Disease Consortium; et al. A nonsense mutation in PDE6H causes autosomal-recessive incomplete achromatopsia. Am. J. Hum. Genet. 2012, 91, 527-532. [CrossRef] [PubMed]

13. Kohl, S.; Zobor, D.; Chiang, W.C.; Weisschuh, N.; Staller, J.; Menendez, I.G.; Chang, S.; Beck, S.C.; Garrido, M.G.; Sothilingam, V.; et al. Mutations in the unfolded protein response regulator ATF6 cause the cone dysfunction disorder achromatopsia. Nat. Genet. 2015, 47, 757-765. [CrossRef] [PubMed]

14. Yoshida, H.; Haze, K.; Yanagi, H.; Yura, T.; Mori, K. Identification of the cis-acting endoplasmic reticulum stress response element responsible for transcriptional induction of mammalian glucose-regulated proteins. Involvement of basic leucine zipper transcription factors. J. Biol. Chem. 1998, 273, 33741-33749. [CrossRef] [PubMed]

15. Haze, K.; Yoshida, H.; Yanagi, H.; Yura, T.; Mori, K. Mammalian transcription factor ATF6 is synthesized as a transmembrane protein and activated by proteolysis in response to endoplasmic reticulum stress. Mol. Biol. Cell 1999, 10, 3787-3799. [CrossRef]

16. Mayer, A.K.; van Cauwenbergh, C.; Rother, C.; Baumann, B.; Reuter, P.; de Baere, E.; Wissinger, B.; Kohl, S.; ACHM Study Group. CNGB3 mutation spectrum including copy number variations in 552 achromatopsia patients. Hum. Mutat. 2017, 38, 1579-1591. [CrossRef]

17. Weisschuh, N.; Sturm, M.; Baumann, B.; Audo, I.; Ayuso, C.; Bocquet, B.; Branham, K.; Brooks, B.P.; Catalá-Mora, J.; Giorda, R.; et al. Deep-intronic variants in CNGB3 cause achromatopsia by pseudoexon activation. Hum. Mutat. 2020, 41, 255-264. [CrossRef]

18. Liang, X.; Dong, F.; Li, H.; Li, H.; Yang, L.; Sui, R. Novel CNGA3 mutations in Chinese patients with achromatopsia. Br. J. Ophthalmol. 2015, 99, 571-576. [CrossRef] 
19. Zelinger, L.; Cideciyan, A.V.; Kohl, S.; Schwartz, S.B.; Rosenmann, A.; Eli, D.; Sumaroka, A.; Roman, A.J.; Luo, X.; Brown, C.; et al. Genetics and Disease Expression in the CNGA3 Form of Achromatopsia: Steps on the Path to Gene Therapy. Ophthalmology 2015, 122, 997-1007. [CrossRef]

20. Fischer, M.D.; Michalakis, S.; Wilhelm, B.; Zobor, D.; Muehlfriedel, R.; Kohl, S.; Weisschuh, N.; Ochakovski, G.A.; Klein, R.; Schoen, C.; et al. Safety and vision outcomes of subretinal gene therapy targeting cone photoreceptors in achromatopsia: A nonrandomized controlled trial. JAMA Ophthalmol. 2020, 138, 643-651. [CrossRef]

21. Wissinger, B.; Gamer, D.; Jägle, H.; Giorda, R.; Marx, T.; Mayer, S.; Tippmann, S.; Broghammer, M.; Jurklies, B.; Rosenberg, T.; et al. CNGA3 mutations in hereditary cone photoreceptor disorders. Am. J. Hum. Genet. 2001, 69, 722-737. [CrossRef]

22. Muraki-Oda, S.; Toyoda, F.; Okada, A.; Tanabe, S.; Yamade, S.; Ueyama, H.; Matsuura, H.; Ohji, M. Functional analysis of rod monochromacy-associated missense mutations in the CNGA3 subunit of the cone photoreceptor cGMP-gated channel. Biochem. Biophys. Res. Commun. 2007, 362, 88-93. [CrossRef] [PubMed]

23. Nakka, P.; Pattillo Smith, S.; O’Donnell-Luria, A.H.; McManus, K.F.; 23 and Me Research Team; Mountain, J.L.; Ramachandran, S.; Sathirapongsasuti, J.F. Characterization of prevalence and health consequences of uniparental disomy in four million individuals from the general population. Am. J. Hum. Genet. 2019, 105, 921-932. [CrossRef] [PubMed]

24. Haudry, C.; de Lonlay, P.; Malan, V.; Bole-Feysot, C.; Assouline, Z.; Pruvost, S.; Brassier, A.; Bonnefont, J.P.; Munnich, A.; Rötig, A.; et al. Maternal uniparental disomy of chromosome 2 in a patient with a DGUOK mutation associated with hepatocerebral mitochondrial DNA depletion syndrome. Mol. Genet. Metab. 2012, 107, 700-704. [CrossRef] [PubMed]

25. Baskin, B.; Geraghty, M.; Ray, P.N. Paternal isodisomy of chromosome 2 as a cause of long chain 3-hydroxyacyl-CoA dehydrogenase (LCHAD) deficiency. Am. J. Med. Genet. A 2010, 152, 1808-1811. [CrossRef] [PubMed]

26. López-Garrido, M.P.; Campos-Mollo, E.; Harto, M.A.; Escribano, J. Primary congenital glaucoma caused by the homozygous F261L CYP1B1 mutation and paternal isodisomy of chromosome 2. Clin. Genet. 2009, 76, 552-557. [CrossRef]

27. Ou, X.; Liu, C.; Chen, S.; Yu, J.; Zhang, Y.; Liu, S.; Sun, H. Complete paternal uniparental isodisomy for chromosome 2 revealed in a parentage testing case. Transfusion 2013, 53, 1266-1269. [CrossRef] [PubMed]

28. Keller, M.C.; McRae, A.F.; McGaughran, J.M.; Visscher, P.M.; Martin, N.G.; Montgomery, G.W. Non-pathological paternal isodisomy of chromosome 2 detected from a genome-wide SNP scan. Am. J. Med. Genet. A 2009, 149, 1823-1826. [CrossRef]

29. Heide, E.; Heide, K.G.; Rodewald, A. Maternal uniparental disomy (UPD) for chromosome 2 discovered by exclusion of paternity. Am. J. Med. Genet. 2000, 92, 260-263. [CrossRef]

30. Berge, K.E.; Tian, H.; Graf, G.A.; Yu, L.; Grishin, N.V.; Schultz, J.; Kwiterovich, P.; Shan, B.; Barnes, R.; Hobbs, H.H. Accumulation of dietary cholesterol in sitosterolemia caused by mutations in adjacent ABC transporters. Science 2000, 290, 1771-1775. [CrossRef]

31. Acampora, D.; Mazan, S.; Avantaggiato, V.; Barone, P.; Tuorto, F.; Lallemand, Y.; Brulet, P.; Simeone, A. Epilepsy and brain abnormalities in mice lacking the Otx1 gene. Nat. Genet. 1996, 14, 218-222. [CrossRef] [PubMed]

32. Mui, S.H.; Kim, J.W.; Lemke, G.; Bertuzzi, S. Vax genes ventralize the embryonic eye. Genes Dev. 2005, 19, 1249-1259. [CrossRef]

33. Ramos, S.B.V. Characterization of delta-N-Zfp3612 mutant associated with arrest of early embryonic development and female infertility. J. Biol. Chem. 2012, 287, 13116-13127. [CrossRef]

34. Kotzot, D. Advanced parental age in maternal uniparental disomy (UPD): Implications for the mechanism of formation. Eur. J. Hum. Genet. 2004, 12, 343-346. [CrossRef]

35. Robinson, W.P.; Lorda-Sanchez, I.; Malcolm, S.; Langlois, S.; Schuffenhauer, S.; Knoblauch, H.; Horsthemke, B.; Schinzel, A.A Increased parental ages and uniparental disomy 15: A paternal age effect? Eur. J. Hum. Genet. 1993, 1, 280-286. [CrossRef]

36. Souzeau, E.; Thompson, J.A.; McLaren, T.L.; De Roach, J.N.; Barnett, C.P.; Lamey, T.M.; Craig, J.E. Maternal uniparental isodisomy of chromosome 6 unmasks a novel variant in TULP1 in a patient with early onset retinal dystrophy. Mol. Vis. 2018, 24, 478-484. [PubMed]

37. Roosing, S.; van den Born, L.I.; Hoyng, C.B.; Thiadens, A.A.; de Baere, E.; Collin, R.W.; Koenekoop, R.K.; Leroy, B.P.; van Moll-Ramirez, N.; Venselaar, H.; et al. Maternal uniparental isodisomy of chromosome 6 reveals a TULP1 mutation as a novel cause of cone dysfunction. Ophthalmology 2013, 120, 1239-1246. [CrossRef] [PubMed]

38. Riveiro-Alvarez, R.; Valverde, D.; Lorda-Sanchez, I.; Trujillo-Tiebas, M.J.; Cantalapiedra, D.; Vallespin, E.; Aguirre-Lamban, J.; Ramos, C.; Ayuso, C. Partial paternal uniparental disomy (UPD) of chromosome 1 in a patient with Stargardt disease. Mol. Vis. 2007, 13, 96-101. [PubMed]

39. Fingert, J.H.; Eliason, D.A.; Phillips, N.C.; Lotery, A.J.; Sheffield, V.C.; Stone, E.M. Case of Stargardt disease caused by uniparental isodisomy. Arch. Ophthalmol. 2006, 124, 744-745. [CrossRef] [PubMed]

40. Rivolta, C.; Berson, E.L.; Dryja, T.P. Paternal uniparental heterodisomy with partial isodisomy of chromosome 1 in a patient with retinitis pigmentosa without hearing loss and a missense mutation in the Usher syndrome type II gene USH2A. Arch. Ophthalmol. 2002, 120, 1566-1571. [CrossRef] [PubMed]

41. Thompson, D.A.; McHenry, C.L.; Li, Y.; Richards, J.E.; Othman, M.I.; Schwinger, E.; Vollrath, D.; Jacobson, S.G.; Gal, A. Retinal dystrophy due to paternal isodisomy for chromosome 1 or chromosome 2, with homoallelism for mutations in RPE65 or MERTK, respectively. Am. J. Hum. Genet. 2002, 70, 224-229. [CrossRef] [PubMed]

42. Richards, S.; Aziz, N.; Bale, S.; Bick, D.; Das, S.; Gastier-Foster, J.; Grody, W.W.; Hegde, M.; Lyon, E.; Spector, E.; et al. Standards and guidelines for the interpretation of sequence variants: A joint consensus recommendation of the American College of Medical Genetics and Genomics and the Association for Molecular Pathology. Genet. Med. 2015, 17, 405-424. [CrossRef] [PubMed] 
43. Tränkner, D.; Jagle, H.; Kohl, S.; Apfelstedt-Sylla, E.; Sharpe, L.T.; Kaupp, U.B.; Zrenner, E.; Seifert, R.; Wissinger, B. Molecular basis of an inherited form of incomplete achromatopsia. J. Neurosci. 2004, 24, 138-147. [CrossRef]

44. Täger, J.; Wissinger, B.; Kohl, S.; Reuter, P. Identification of chemical and pharmacological chaperones for correction of traffickingdeficient mutant CNGA3 channels. Mol. Pharmacol. 2021, 99, 460-468. [CrossRef] [PubMed]

45. Täger, J.; Kohl, S.; Birch, D.G.; Wheaton, D.K.H.; Wissinger, B.; Reuter, P. An early nonsense mutation facilitates the expression of a short isoform of CNGA3 by alternative translation initiation. Exp. Eye Res. 2018, 171, 48-53. [CrossRef] [PubMed] 